\title{
Elephant seal foraging dives track prey distribution, not temperature: Comment on McIntyre et al. (2011)
}

\author{
Philipp H. Boersch-Supan ${ }^{1,2}$, Lars Boehme ${ }^{3}$, Jane F. Read ${ }^{4}$, Alex D. Rogers ${ }^{2, *}$, \\ Andrew S. Brierley ${ }^{1, * *}$ \\ ${ }^{1}$ Pelagic Ecology Research Group, Scottish Oceans Institute, University of St. Andrews, Fife KY16 8LB, UK \\ ${ }^{2}$ Department of Zoology, University of Oxford, Oxford OX1 3PS, UK \\ ${ }^{3}$ Sea Mammal Research Unit, Scottish Oceans Institute, University of St. Andrews, Fife KY16 8LB, UK \\ ${ }^{4}$ National Oceanography Centre Southampton, Natural Environment Research Council, Southampton SO14 3ZH, UK
}

\begin{abstract}
McIntyre et al. (2011; Mar Ecol Prog Ser 441:257-272) concluded that climate change-related ocean warming may lead to deeper foraging dives by southern elephant seals as their prey is forced into deeper depths. They further assert that fitness for the seals will be reduced because of greater physiological costs for deep dives and the assumption that deep foraging is less successful. Their conclusions are based on an observed correlation between a temperature index and elephant seal diving depth but do not include any observations of prey. We recently observed pronounced differences in the vertical distribution of pelagic biota - biota that may well include elephant seal prey - across the same frontal zone considered by McIntyre et al. (2011) and believe that their suggested link between temperature and diving depth is actually a link between predators and distinct prey fields - a reflection of adaptive foraging behaviour in a complex and dynamic pelagic system. As such, the analysis of McIntyre et al. (2011) is uninformative about likely impacts of ocean warming.
\end{abstract}

KEY WORDS: Climate change $\cdot$ Effect size $\cdot$ Prey field $\cdot$ Vertical structure $\cdot$ Southern elephant seal $\cdot$ Foraging ecology $\cdot$ Deep scattering layer

Resale or republication not permitted without written consent of the publisher

\section{Introduction}

McIntyre et al. (2011) studied the diving behaviour of southern elephant seals Mirounga leonina from Marion Island (southwest Indian Ocean) in relation to a number of hydrographic and biological variables, and observed a significant positive correlation between a temperature index and the diving depth. They concluded that diving behaviour is influenced by ocean temperature, and further, that as the Southern Ocean warms because of climate change, elephant seals will have to dive deeper. However, their analysis and the employed predictors are not suitable to detect effects of climate change for the following reasons: (1) The temperature index they use is likely to be a proxy variable for water mass and not an ocean warming indicator; (2) some statistically significant model results are not biologically meaningful; (3) data on the pelagic environment of the southwest Indian Ocean from recent transects across the subtropical convergence and Subantarctic Front demonstrate step changes in the vertical structure (data presented in this Comment) and community composition of pelagic biota (authors' unpubl. data), indicating distinct prey fields on either side of the frontal zone; (4) several alternative explanations such as seasonal and regional effects on diving depth were not explored in the analysis; and (5) the asserted link 
between time-at-depth and foraging success is speculative. Here, we address these issues and propose an alternative explanation for dive-depth variability based on prey distribution.

\section{Temperature, frontal zone positions and the use of daily averages}

The temperature index employed by McIntyre et al. (2011) is the daily average of the maximum temperature recorded below $100 \mathrm{~m}$ during a dive ( $\left.T_{\max } 100\right)$. As the thermal water column structure north of the Polar Front is usually characterised by a shallow temperature maximum and a monotonic decrease in temperature (Belkin \& Gordon 1996, Boehme et al. 2008), $T_{\max } 100$ is likely to represent the temperature at, or near $100 \mathrm{~m}$ (Fig. 1), a depth that is 300 to $700 \mathrm{~m}$ shallower than the mean foraging depths reported by McIntyre et al. (2011; see our Fig. 2B). Given that they base their conclusions on the assumption that the vertical distribution of prey species will change with ocean warming, it would have been more appropriate for their models to be based on the in situ temperature at foraging depth.

Judging from temperature profiles that we collected during a crossing of the Agulhas Front, South-

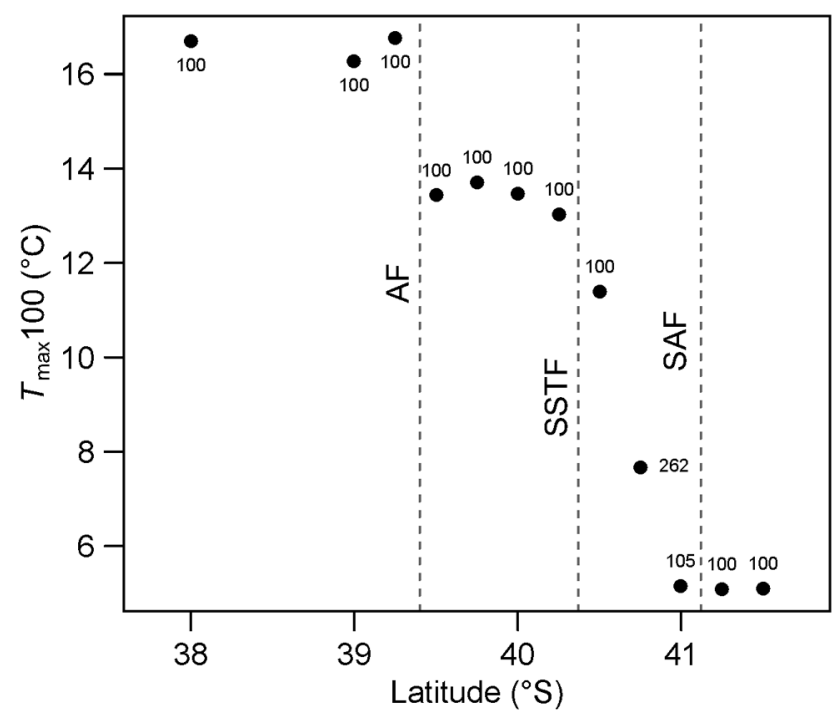

Fig. 1. Relationship between the maximum temperature recorded below $100 \mathrm{~m}\left(T_{\max } 100\right)$, the depth at which $T_{\max } 100$ was recorded ( $T_{\max } 100$.depth) and frontal locations for a CTD transect crossing the Subantarctic Frontal zone in the southwest Indian Ocean. Numerals indicate $T_{\max }$ 100.depth (m). Dashed lines: front locations (determined from full CTD casts according to criteria from Belkin \& Gordon 1996). $T_{\max } 100$ indices were calculated according to McIntyre et al. (2011). AF: Agulhas Front, SSTF: Southern Subtropical Front, SAF: Subantarctic Front ern Subtropical Front and Subantarctic Front in late 2009 (Rogers et al. 2009), the $T_{\max } 100$ index is closely related to the geographic location of a temperature profile relative to the individual fronts (Fig. 1) and therefore a proxy for water mass. In fact, the temperature at $100 \mathrm{~m}$ has been used for the very definition of frontal locations (Belkin \& Gordon 1996). In addition to $T_{\max } 100$, McIntyre et al. (2011) employ a factor in their initial models to indicate the position of a dive relative to the fronts. This factor is dropped in most of their final models, possibly because of collinearity with the temperature index based on the relationship between $T_{\max } 100$ and water mass. Furthermore, the temperature variation encountered by foraging elephant seals in the frontal zone is likely to be influenced by smaller scale features (days, 10s of $\mathrm{km}$ ), such as mesoscale eddies (Bailleul et al. 2010, Dragon et al. 2010, 2012), while the location of a dive relative to the fronts would only explain temperature variation on large temporal and spatial scales (months, 100s of km). This scale-dependent temperature variation likely makes $T_{\max } 100$ a better predictor for any variation in diving behaviour and would explain the result of the model selection procedure.

In addition to $T_{\max } 100$ being a water mass proxy rather than an ocean warming indicator, the use of daily temperature averages is prone to confound the relationship between temperature, water mass, relative position of a dive in relation to the fronts, and seal diving behaviour, as elephant seals are capable of travelling over $100 \mathrm{~km} \mathrm{~d}^{-1}$ (Biuw et al. 2003) and forage in a highly variable environment.

\section{Effect sizes and variability in predictors and model results}

McIntyre et al. (2011) set out to investigate potential effects of ocean warming on elephant seals. Their analysis, however, does not distinguish between climate effects (small, $<1^{\circ} \mathrm{C}$ ) and natural environmental variation (large, $>10^{\circ} \mathrm{C}$ ) in their study area, especially regarding the magnitude of the effect that these distinct sources of variation have on ocean temperature. Elephant seals forage in extremely diverse habitats where oceanographic and topographic features such as fronts, eddies, seamounts, and shelf breaks influence prey availability on a variety of spatial and temporal scales (Biuw et al. 2007, Charrassin et al. 2008, Simmons et al. 2010, Maxwell et al. 2011). While the biophysical coupling associated with these diverse habitats and processes is influenced by climate, the effect of present climate change is very small com- 

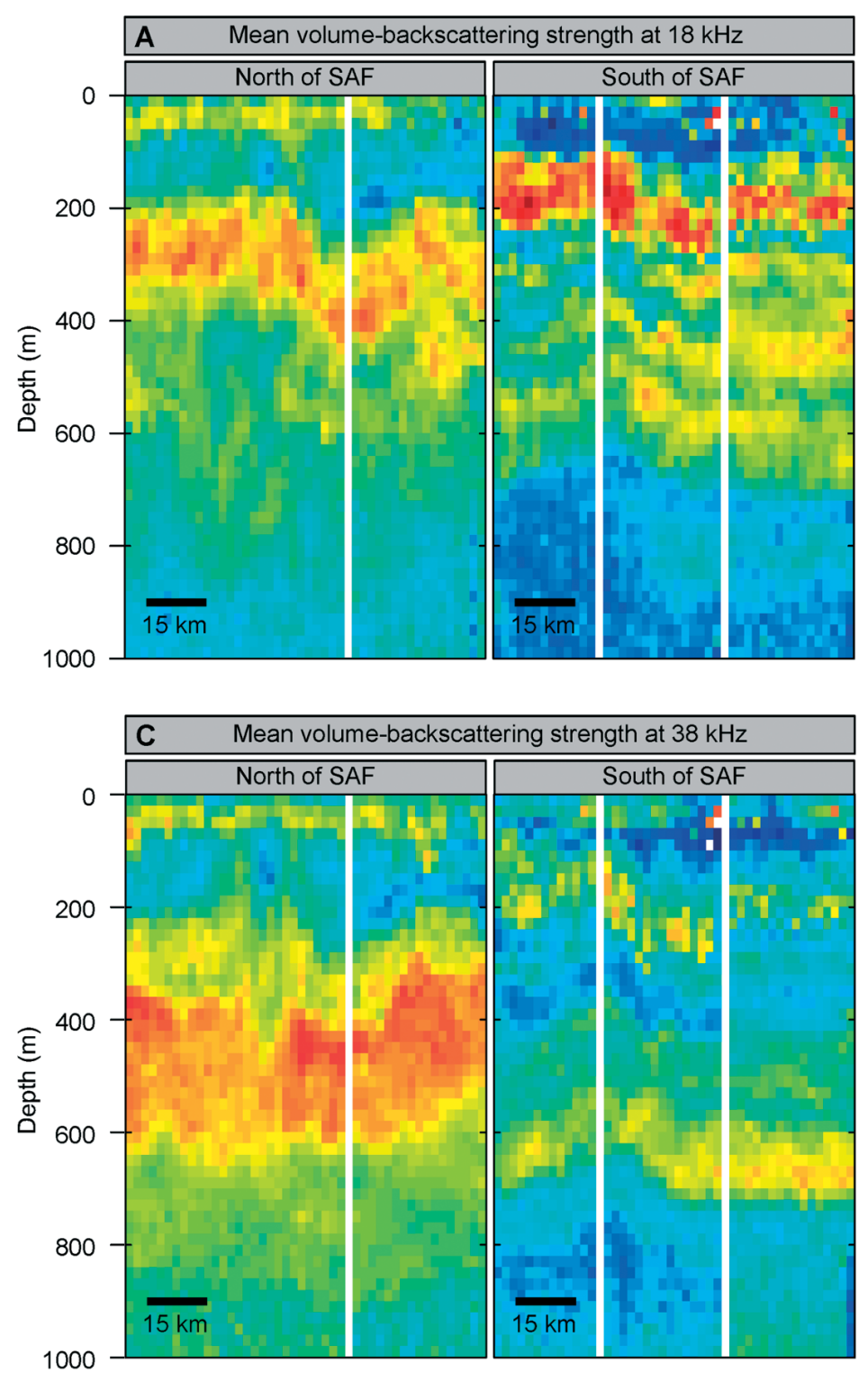

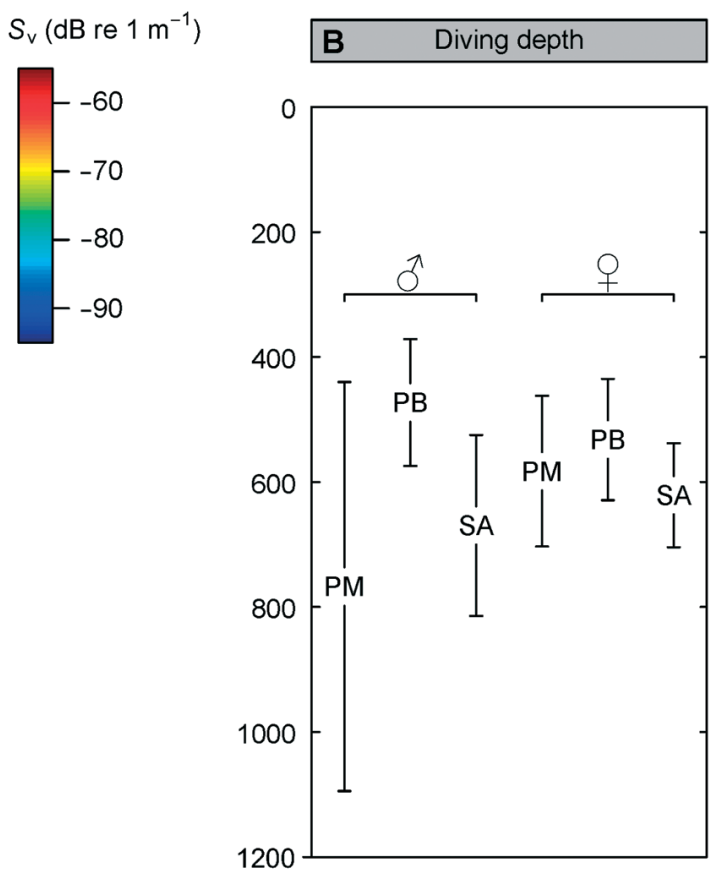

Fig. 2. Representative echograms of the vertical structure of daytime pelagic scattering layers in the frontal zone of the southwest Indian Ocean. Horizontal axis in (A) and (C) represents along-track distance (from left to right), as indicated by the scale bars. Data at CTD stations were excluded because of substantially elevated noise levels and echoes from the CTD rosette (white vertical lines in $\mathrm{A}$ and $\mathrm{C}$ ). (A) Mean volume-backscattering strength $\left(S_{\mathrm{v}}\right)$ at $18 \mathrm{kHz}$; $(\mathrm{B})$ mean $\pm \mathrm{SD}$ daytime diving depths of different elephant seal groups (after McIntyre et al. 2011, their Table 2); (C) mean $S_{\mathrm{v}}$ at $38 \mathrm{kHz}$. SAF: Subantarctic Front, PM: post-moult, PB: post-breeding, SA: subadult pared to the environmental variability within and between the habitats.

The surface waters around Marion Island have

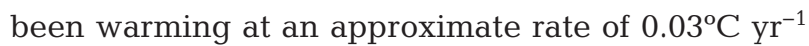
in recent decades (Mélice et al. 2003). At intermediate depths (700 to $1000 \mathrm{~m}$ ), warming rates have been

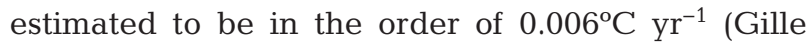
2002). In contrast to this, the $T_{\max } 100$ index employed by McIntyre et al. (2011) has a range of approximately $10^{\circ} \mathrm{C}$ across the frontal zone (Fig. 1). It is difficult to see how their model could distinguish a climate signal from environmental variability when the latter is several orders of magnitude greater. In addition, any measurable climate effect on ocean temperature would be within the measurement error of at least 1 of the 2 sensor types used by McIntyre et al. (2011). Boehme et al. (2008) show that the temperature accuracy of the CTD satellite-relay data loggers (SRDLs) is between \pm 0.005 and $\pm 0.03^{\circ} \mathrm{C}$ after postdeployment corrections. However, this does not apply to the temperature-only Series 9000 SRDL, which incorporates an uncalibrated thermistor as a temperature probe. The manufacturer (Sea Mammal Research Unit, University of St. Andrews, UK) claims an accuracy of $\pm 0.1^{\circ} \mathrm{C}$ (www.smru.st-andrews.ac.uk/ protected/downloads/SRDL9000X.pdf) but does not quantify the long-term stability of accuracy.

Concerning their model results, McIntyre et al. (2011) highlight the statistical significance of the relationship between temperature and diving depths. 
The biological meaning of this result is, however, not explicitly discussed, and the reporting of log-transformed and untransformed coefficients side-by-side does not help the interpretation of model results. Their estimate for the temperature effect on logtransformed adult male diving depth is reported as 0.03 , which approximately translates into a $1 \mathrm{~m}$ diving depth increase per $1^{\circ} \mathrm{C}$ temperature increase. Even under drastic ocean warming, a few metres of difference in diving depth are ecologically meaningless, as oscillations in scattering layer depth of $10 \mathrm{~s}$ of metres are common (cf. Fig. 2A,C). The effect is much more pronounced for female seals at approximately $10 \mathrm{~m}^{\circ} \mathrm{C}^{-1}$ (McIntyre et al. 2011), but this is also of little biological relevance in the context of minute warming rates. The female result does, however, become ecologically meaningful when considering the much greater temperature difference between water masses. Using our temperature data and McIntyre et al.'s (2011) estimate, female southern elephant seals are expected to dive approximately 100 m deeper north of the Subantarctic Front.

\section{Vertical structure of pelagic biota across fronts and eddies}

We have surveyed the pelagic environment of the southwest Indian Ocean (Rogers et al. 2009) and collected data on the distribution and diversity of zooplankton and nekton in the top $1000 \mathrm{~m}$ of the water column using a calibrated multi-frequency echosounder and a midwater trawl. Our results confirm that the Subantarctic Front is a significant biogeographic boundary (e.g. Pakhomov et al. 1994). The environments on either side of the front are characterised by distinct micronekton assemblages (A. D. Rogers et al. unpubl.) as well as marked differences in the vertical structure of biomass distribution and diel vertical migration behaviour.

The environment north of the front is characterized by a thin surface-scattering layer, a very thick deepscattering layer and moderate amounts of diffuse backscatter at depths below $700 \mathrm{~m}$. The scattering layer structure south of the front is much more complex, featuring at least 4 distinct daytime layers at different depths but only weak backscatter in the deepest strata (Fig. 2 A,C). Scattering layers on either side of the front follow different patterns of diel vertical migration. North of the front, a substantial proportion of $38 \mathrm{kHz}$ backscatter is located in a nonmigratory deep-scattering layer, whereas the main scattering layer at $18 \mathrm{kHz}$ is migratory, rising from
$300 \mathrm{~m}$ to the surface at night. South of the front the shallower layers show more extensive vertical migration than the deeper ones at both frequencies. The top-most layer ascends from approximately 200 to $50 \mathrm{~m}$ at night while the deepest layer remains stationary.

Elephant seals are wide-ranging long-lived animals in a dynamic and heterogeneous environment and must be adapted to large variations in prey availability in time and space (Biuw et al. 2007). Their foraging behaviour is ultimately driven by prey distributions (Hindell et al. 2011, Dragon et al. 2012), and elephant seals are able to adapt their diving behaviour seasonally and in differing hydrographic conditions (Bailleul et al. 2007, Biuw et al. 2007, 2010). A direct relationship between observed scattering layer depth and marine mammal foraging behaviour is not always apparent, especially when concurrent in situ data are unavailable. Some studies have demonstrated remarkable spatio-temporal overlap between foraging predators and backscatter features (e.g. Fiedler et al. 1998), while in others the correlations are less pronounced (Hazen \& Johnston 2010). The mean diving depths reported by McIntyre et al. (2011, their Table 2) do not match exactly any of the echogram features observed by us, which is not surprising considering that the dive data were averaged over $4 \mathrm{yr}$ and 1000s of $\mathrm{km}$ of seal tracks. The comparison does, however, show that elephant seal foraging depths overlap with pelagic scattering layers on either side of the front (Fig. 2). Furthermore, there are some clues that may explain the observed positive relationship between temperature and diving depth: the dominant $18 \mathrm{kHz}$ scattering layer north of the front has its peak intensity at around $300 \mathrm{~m}$ (maximum mean volume backscattering strength, $S_{\mathrm{v} i}$ MacLennan et al. 2002), ca. $100 \mathrm{~m}$ deeper than the dominant layer south of the front (maximum $S_{\mathrm{v}}$ at $200 \mathrm{~m}$ ). In addition to this, mean $S_{\mathrm{v}}$ at both frequencies at depths in excess of $700 \mathrm{~m}$ is more than twice as intense north of the front than south of it $\left(\Delta S_{\mathrm{vi}} 18 \mathrm{kHz}=\right.$ $4.04 \mathrm{~dB}$ re $1 \mathrm{~m}^{-1} ; \Delta S_{\mathrm{v} ;} 38 \mathrm{kHz}=3.49 \mathrm{~dB}$ re $1 \mathrm{~m}^{-1}$ ).

Little is known about the vertical structure of pelagic biota in mesoscale eddies in the southwest Indian Ocean, but the foraging of southern elephant seals in eddies in this region has been documented (Bailleul et al. 2010, Dragon et al. 2010, 2012). There is also evidence from the north Atlantic that the vertical distribution of pelagic animals in eddies can be markedly different from that in surrounding waters (Conte et al. 1986), including significant increases in deep (600 to $1200 \mathrm{~m}$ ) biomass in warm core eddies (Godø et al. 2012). 


\section{Alternative predictors of diving behaviour}

McIntyre et al. (2011) partitioned their dive data to account for differences between the sexes and age classes of elephant seals, as well as diel differences in behaviour, but seasonal and/or regional effects were not sufficiently considered. They briefly discuss the fact that the 'track day' variable is a significant predictor in all of their models for female seals, but no attempt is made to investigate seasonality (e.g. by exploring 'day of the year' as a predictor; see also Biuw et al. 2010), even though the data presented for the subadult male individual OO405 indicate a nonrandom seasonal trend for diving depth, encountered temperature and time-at-depth. The possibility of detecting seasonal effects is further hindered by the restriction to the first $150 \mathrm{~d}$ at sea for the females' data. Although the seasonality of the vertical distribution of mesopelagic communities is poorly understood, it has been well established that seasonal processes influence scattering layer structures (e.g. Staby et al. 2011).

As we suggest here, spatial effects can play an important role (see also Anderson et al. 2005). The relationship between foraging location and ocean temperature has been discussed in detail in 'Temperature, frontal zone positions and the use of daily averages' above, but foraging location is also important when considering differences between pelagic and benthic dives (Maxwell et al. 2011). A variable for bottom depth was a significant predictor for dive depth in some of McIntyre et al.'s (2011) models. While there is a close relationship between bottom and diving depth for benthic dives, bottom depth isin our experience-often a poor predictor in pelagic systems where the ecology at foraging depth is largely decoupled from bentho-pelagic processes occurring at depths hundreds to thousands of metres deeper. A factor to distinguish between benthic and pelagic dives might have been more informative both biologically and in terms of predictive value.

\section{Time-at-depth and foraging success}

McIntyre et al. (2011) did not assess foraging success or body condition of the seals they studied but suggest that the shorter time-at-depth during deeper dives points to less successful foraging. In the absence of in situ behavioural data, constructing a link between time-at-depth and foraging success is speculative. One could argue by the same token that foraging in warmer water is more efficient, or that the energetic costs of deeper diving are balanced by reduced heat loss in warmer water.

Furthermore, a comparison of time-at-depth between water masses may be confounded by adaptive foraging behaviour for different prey species. Trawl data from our 2009 survey indicate distinct pelagic assemblages for decapod and lophogastrid crustaceans (T. Letessier pers. comm.), cephalopods (V. Laptikhovsky pers. comm.) and fishes (K. Kemp pers. comm.) across the Subantarctic Front. Prey speciesspecific diving behaviour is poorly understood in southern elephant seals but has been observed in other pinnipeds (e.g. Bowen et al. 2002).

\section{Conclusions}

Climate change is likely to affect elephant seals in the southern Indian Ocean, for example through the intensification of eddy activity (Meredith \& Hogg 2006), which may change the locations and temporal availability of foraging opportunities. However, the correlation between ocean temperature and diving behaviour reported by McIntyre et al. (2011) is likely a demonstration of adaptive foraging behaviour in distinct pelagic biomes rather than a climatic effect. Furthermore, such adaptive behaviours are likely to vary at different scales reflecting scales of patchiness in food availability (Simmons et al. 2010).

Simplistic correlative analyses of environmental variables and behavioural responses are of limited usefulness for both studies of climate change and predator-prey interactions, particularly in dynamic pelagic systems. An investigation of climate change effects would require a different modelling framework, most importantly one where temperature data were stratified between water masses, and seasonal effects were accounted for. Studies of predator-prey interactions should include prey distributions as well as potential indicators of foraging success and preyspecific foraging behaviour (e.g. Biuw et al. 2003, Dragon et al. 2012) rather than just environmental proxies.

Acknowledgements. The data collection was undertaken as part of the Southwest Indian Ocean Seamounts Project (www.iucn.org/marine/seamounts) supported by the the EAF Nansen Project, the Food and Agriculture Organization of the United Nations, the Global Environment Facility, the International Union for the Conservation of Nature, the Natural Environment Research Council (Standard Research Grant NE/F005504/1), the Leverhulme Trust (Grant no. F00390C) and the Total Foundation. We thank K. Kemp, $\mathrm{V}$. Laptikhovsky and T. Letessier for providing preliminary 
species diversity data for the trawl samples. P.H.B.S. was supported by a Cusanuswerk doctoral fellowship, and a Lesley \& Charles Hilton-Brown Scholarship, University of St. Andrews.

\section{LITERATURE CITED}

Anderson CIH, Brierley AS, Armstrong F (2005) Spatio-temporal variability in the distribution of epi- and mesopelagic acoustic backscatter in the Irminger Sea, North Atlantic, with implications for predation on Calanus finmarchicus. Mar Biol 146:1177-1188

Bailleul F, Charrassin J, Monestiez P, Roquet F, Biuw M, Guinet C (2007) Successful foraging zones of southern elephant seals from the Kerguelen Islands in relation to oceanographic conditions. Philos Trans R Soc B 362: 2169-2181

Bailleul F, Cotté C, Guinet C (2010) Mesoscale eddies as foraging area of a deep-diving predator, the southern elephant seal. Mar Ecol Prog Ser 408:251-264

Belkin I, Gordon A (1996) Southern Ocean fronts from the Greenwich meridian to Tasmania. J Geophys Res 101: 3675-3696

Biuw M, McConnell B, Bradshaw C, Burton H, Fedak M (2003) Blubber and buoyancy: monitoring the body condition of free-ranging seals using simple dive characteristics. J Exp Biol 206:3405-3423

Biuw M, Boehme L, Guinet C, Hindell M, and others (2007) Variations in behavior and condition of a southern ocean top predator in relation to in situ oceanographic conditions. Proc Natl Acad Sci USA 104:13705-13710

Biuw M, Nøst O, Stien A, Zhou Q, Lydersen C, Kovacs K (2010) Effects of hydrographic variability on the spatial, seasonal and diel diving patterns of southern elephant seals in the eastern Weddell Sea. PLoS ONE 5:e13816

Boehme L, Meredith M, Thorpe S, Biuw M, Fedak M (2008) Antarctic circumpolar current frontal system in the south Atlantic: monitoring using merged Argo and animalborne sensor data. J Geophys Res 113:C09012. doi: 10.1029/2007JC004647

Bowen W, Tully D, Boness D, Bulheier B, Marshall G (2002) Prey-dependent foraging tactics and prey profitability in a marine mammal. Mar Ecol Prog Ser 244:235-245

Charrassin JB, Hindell M, Rintoul S, Roquet F, and others (2008) Southern Ocean frontal structure and sea-ice formation rates revealed by elephant seals. Proc Natl Acad Sci USA 105:11634-11639

Conte M, Bishop J, Backus R (1986) Nonmigratory, 12-kHz, deep scattering layers of Sargasso Sea origin in warmcore rings. Deep-Sea Res A Oceanogr Res Pap 33: 1869-1884

> Dragon A, Monestiez P, Bar-Hen A, Guinet C (2010) Linking foraging behaviour to physical oceanographic structures: southern elephant seals and mesoscale eddies east of Kerguelen Islands. Prog Oceanogr 87:61-71

Dragon A, Bar-Hen A, Monestiez P, Guinet C (2012) Horizontal and vertical movements as predictors of foraging

Editorial responsibility: Christine Paetzold, Oldendorf/Luhe, Germany success in a marine predator. Mar Ecol Prog Ser 447: 243-257

Fiedler P, Reilly S, Hewitt R, Demer D, and others (1998) Blue whale habitat and prey in the California Channel Islands. Deep-Sea Res II 45:1781-1801

Gille ST (2002) Warming of the Southern Ocean since the 1950s. Science 295:1275-1277

Godø OR, Samuelsen A, Macaulay GJ, Patel R, and others (2012) Mesoscale eddies are oases for higher trophic marine life. PLoS ONE 7:e30161

Hazen E, Johnston D (2010) Meridional patterns in the deep scattering layers and top predator distribution in the central equatorial Pacific. Fish Oceanogr 19:427-433

Hindell M, Bost C, Charrassin J, Gales N, and others (2011) Foraging habitats of top predators, and areas of ecological significance on the Kerguelen Plateau. In: Duhamel G, Welsford D (eds) The Kerguelen Plateau: marine ecosystem and fisheries. Société Française d'Ichtyologie, Paris, p 203-215

MacLennan DN, Fernandes PG, Dalen J (2002) A consistent approach to definitions and symbols in fisheries acoustics. ICES J Mar Sci 59:365-369

Maxwell S, Frank J, Breed G, Robinson P, and others (2011) Benthic foraging on seamounts: a specialized foraging behavior in a deep-diving pinniped. Mar Mamm Sci 28(3):E333-E344

> McIntyre T, Ansorge I, Bornemann H, Plötz J, Tosh C, Bester M (2011) Elephant seal dive behaviour is influenced by ocean temperature: implications for climate change impacts on an ocean predator. Mar Ecol Prog Ser 441: $257-272$

Mélice J, Lutjeharms J, Rouault M, Ansorge I (2003) Seasurface temperatures at the sub-Antarctic islands Marion and Gough during the past 50 years. S Afr J Sci 99: 363-366

> Meredith M, Hogg A (2006) Circumpolar response of Southern Ocean eddy activity to a change in the southern annular mode. Geophys Res Lett 33:L16608. doi:10.1029/ 2006GL026499

> Pakhomov E, Perissinotto R, McQuaid C (1994) Comparative structure of the macrozooplankton/micronekton communities of the Subtropical and Antarctic Polar Fronts. Mar Ecol Prog Ser 111:155-169

Rogers A, Alvheim O, Bemanaja E, Benivary D and others (2009) Preliminary cruise report 'Dr. Fridtjof Nansen' southern Indian Ocean seamounts (IUCN/UNDP/ ASCLME/NERC/EAF Nansen Project 2009 Cruise 410) 12th November-19th December. International Union for Conservation of Nature, Gland

Simmons S, Crocker D, Hassrick J, Kuhn C, Robinson P, Tremblay Y, Costa D (2010) Climate-scale hydrographic features related to foraging success in a capital breeder, the northern elephant seal Mirounga angustirostris. Endang Species Res 10:233-243

Staby A, Røstad A, Kaartvedt S (2011) Long-term acoustical observations of the mesopelagic fish Maurolicus muelleri reveal novel and varied vertical migration patterns. Mar Ecol Prog Ser 441:241-255

Submitted: March 30, 2012; Accepted: June 21, 2012 Proofs received from author(s): July 20, 2012 